\title{
Naturalizing Social Class as a Moral Category on Swedish Mainstream Television
}

\author{
Peter Jakobsson \& Fredrik Stiernstedt
}

\begin{abstract}
This paper presents an analysis of how social class is constructed as a moral category on Swedish mainstream television. Practices of categorisation by the media is an important area of study since these practices are part of a process of co-construction of social categories that are offered to media users as cognitive tools and frames for navigating the social landscape. Based on a content analysis of television in Sweden, we show that the medium of television categorises people appearing on television along the social divisions of class and constructs class as a moral category, with a lower moral value assigned to the working class in comparison to the middle and upper class.
\end{abstract}

Keywords: class, ideology, categorisation, valuation, content analysis

\section{Introduction}

The concept of class, as a way to understand society and social relations, has been somewhat marginalised in the Swedish public debate during the last decades. Furthermore, in the media and popular culture in general, the question of class is rarely mentioned or made explicit, but rather supressed and avoided (Bromley 2000; Bullock, Fraser Wyche \& Williams 2001; Mantsios 2003). The irony is that, during the same period, economic and social inequalities have increased, more so in Sweden than in any other country in the OECD (2017), and social class has come to play an increasing role in determining people's lives (Oskarson, Bengtsson \& Berglund 2010). The lack of explicit references to understandings of social class in the media and popular culture does not mean, however, that social class has become irrelevant for how media is consumed and produced. Scholars have argued that social class is, for example, essential for reality television, in that social class is used to create drama in this genre and how social class matters for the interpretation of these shows by their audiences (Palmer 2004; Perks 2007; Meloy 2009; Wood \& Skeggs 2011). Based on a content analysis of television in Sweden, we argue that the importance of class goes even further than that. In this article, the aim is to show that the medium of television categorises people appearing on television along the social divisions of class, and constructs class as a moral category, with a lower 
moral value assigned to the working class in comparison to the middle and upper class, even while class is rarely explicitly mentioned or thematised. This article thus makes an empirical contribution to the study of the relation between media and social class by showing how social class is valued on mainstream television.

The theoretical focus in this article is categorisation and category formation. Categories, according to the theoretical framework developed here, precede and are foundational for individual symbols and representations. The empirical interest in television is based on the media's role in the cultural process through which certain categories come to be taken for granted and accepted as a universal condition of the social world (Couldry 2011, 2008). Adopting the language of ideology critique, we discuss the role of the media as a process of naturalisation, through which certain categorical divisions and valuations comes to be taken as common sense. An important methodological argument in the article is the usefulness of content analysis for analysing the media's role in such category formation. Analyses of individual texts are important for studying ideological functions of specific texts, but such studies do not consider the media's overall world-building capacities through the construction of social categories that are recurrent throughout the entire landscape of televisual content.

The empirical parts of the paper present an analysis of the televisual landscape of one specific place (Sweden) in one moment in time (2015) and aim to answer the following questions: Are people appearing on television categorised along the lines of social class? Is social class constructed as a moral category on television, and if so, in what ways? How can the categorisation of people appearing on television be understood from the perspective of a theory of ideology?

In the first part, we discuss the theoretical concepts used, including ideology, categorisation and naturalisation. In the second part of the article, after a description of our methodology, we present an analysis of how mainstream television in Sweden in 2015 categorises and attributes moral value to people appearing on television, along the divisions of social class. We show that class, even though seldom manifestly mentioned or expressed, systematically structures televisual output. For example, working-class people on television are portrayed as lacking individuality, social skills, and authority, and are generally conceived as less important than people belonging to the middle and upper classes. Based on these observations we argue that Swedish television constructs class as moral category.

\section{Ideology, naturalisation and social categories}

John B. Thompson (1984: 4) argues that ideology is "the ways in which meaning (or signification) serves to sustain relations of domination". A key aspect of ideology is naturalisation, the ideological process through which relations and conditions that have explanations in human history instead come to be understood as given and unchangeable and thus beyond the realm of political struggle (Thompson 1990). This dimension of ideological processes is here taken as a starting point for a theoretical discussion about the contribution of television to the naturalisation of a certain way of valuing social class. We argue that the recurring patterns of valuation of people in televisual content is not only systematically divided along class-based lines (in a process of categorisation) but also that such valuation is ideological and hence has social consequences. While social 
class mainly refers to the individuals' place in the social structure based on their relations to the means of production (Therborn 1999), the moral valuation of the different class positions is not given by those relations, but has to be socially and symbolically produced. Attempting to theorise the role of the media in processes of naturalisation, we follow Nick Couldry (2008), who argues, in dialogue with a wide range of theoretical approaches, that an interesting venue for research might be opened if we look to media's role in the co-construction of basic social categories. What are the categories of media discourse; how do they function across media and different genres; how do they structure and assign values to the social world?

Categorisation and category formation are central concerns in studies of psychology and cognition (Lakoff 1987; McGarty 1999), but the creation and maintenance of categories is at the very heart of human action and society, and they hence also stretch beyond the realms of individual minds and into social practices and discourse. Accordingly, within sociology, studies of categories and categorisation has long been of central concern (Durkheim \& Mauss 1963). To categorise is a social practice; individuals in society are categorised through various systems (state, science, surveillance) and by other groups and individuals. But they also, and at the same time, classify and categorise themselves, and - to follow the work of Pierre Bourdieu (1989) - they classify and categorise depending upon their position within various categories, the sum of which Bourdieu describes as the habitus of the individual. Categorisations are hence symbolic and material at the same time (Bourdieu 1989). The media system creates and maintains social categories symbolically, but it does this in a way that is not independent from how social categories are produced through the mode of production or through bureaucracy and statistics.

It has been pointed out, however, that one thing that is missing in Bourdieu's theory is the moral dimension of categories and categorisation and the fact that categorisation always involves an element of valuation and the drawing of moral boundaries (Skeggs 2004; Sayer 2005; Harrits \& Møller 2011). Such moral valuations are present not only in the categorisation practices of individuals or groups but also in the operation of the media - for example, through reality TV's spectacularisation of "the failures of selfresponsibility" (Skeggs 2005: 974). As shown in this article, however, moral valuations by the media also occur through more subtle means, for example, by patterns of relative invisibility or through the repeated denial of voice to a particular social group. Such examples highlight the potential connections between the media and feelings of inferiority and superiority, shame and disgust, that characterise class relations in our present society (Skeggs 2004).

Couldry further argues that it is "not the factual content of media [but rather] elements and categories of media discourse" that through processes of naturalisation "become embedded in everyday practice and so become self-reproducing simply by being taken-for-granted as "natural"' (Couldry 2008: 78). Following his previous research (Couldry 2003) on the myths of the modern media, Couldry exemplifies the media's role in category formation with "media celebrities", and distinctions such as those between "ordinary people" and "media people". That those categories are operative on the level of social action is evident, for example, from the way that we automatically notice, and change our behaviour accordingly, when a celebrity enters the room. The categories we are interested in, relating to social class, are partly different from the categories analysed 
by Couldry, since these latter categories are, in a certain sense, endemic to the media. The construction of class categories, as well as the attachment of value and hierarchy to those categories, happens mainly outside of media representations - in everyday life, at the workplace, in official statistics - and lies at the heart of the capitalist mode of production. ${ }^{1}$ The role of the media in constructing class as a social category should thus be seen as that of a co-constructor and we do not argue that television creates or alter the social categories of class, at least not in the shorter time perspective. What we do argue is that television partakes in the valuation of class, and that these valuations might have ideological effects. In this sense categorisation and valuation might of course in the long run effect the class composition and the categories of class, for example, through blocking political action directed against class society. In this sense, we agree with Rosemary Crompton's (2008) assertion that material and symbolic dimensions of class is only possible to separate analytically, while they, in reality, are intertwined in messy and sometimes unpredictable ways.

An important point of this article is the methodological consequences that follow from a focus on naturalisation through category formation. Our argument is that if we are to analyse the media's role in the naturalisation of a certain descriptive or evaluative characterisation of the social world, our interest should not be directed toward single media texts and their interpretation. Instead, it is more useful to study the broader patterns of media texts, and the structures and categories underlying these texts that often are not evoked explicitly in the text or noticed consciously by the viewer, but are still there as a basic structure within which the drama or the news story unfolds. Although these structures change over time and can in themselves be both contradictory and ambiguous, it can still be demonstrated that they exist in a specific form at a certain point in time, as we do in this article. Even if there are some variations in how categories are constructed and valued across different genres, it is precisely their existence and appearance across genres that turns certain representations into "categories", rather than merely signs or symbols. If television plays a role in the construction of social class as a category, as we argue here, it is thus not by the explicit evocation of the concept of social class by the producers or by the audience, but by the implicit categorisation that arises through the systematic and patterned representations of the different social classes as having low or high value. The fact that the category of social class is seldom explicit in the televisual material does not mean that it is unimportant or do not serve ideological purposes. The systematic valuation of people with different positions in relation to social production (i.e. different jobs and occupations) creates class as an underlying categorisation in the analysed television materials, in ways similar to how social class is an underlying - but operative - dimension in other social processes - for example, in everyday life.

Content analysis, the method used in the empirical study presented here, has previously been criticised, specifically from the perspective of a theory of ideology. In an influential text, Stuart Hall (Hall 1977) argued that content analysis, which often mainly analyses the manifest elements and the textual surface in, for example, television output, would fail to grasp the complex work of ideology, which takes place primarily in the deep structures of media texts. Another critique towards ideological analysis focusing on textual expression is the fact that such methods have definitive shortcomings to understanding the ideological effects, and Thompson (1990), among others, has suggested that such approaches need to be supplemented with audience studies (interviews, observa- 
tions, surveys) in order to remedy the empirical shortcomings of solely focusing on texts. We agree with these critical remarks and acknowledge that close readings, hermeneutic approaches, and audience studies are necessary complements in ideological analyses. We do believe, however, that the analyses of large text corpora and the systematic patterns within them (as facilitated by content analysis) reveals the context, the underlying value system, that functions as the interpretative context to the textual strategies of individual texts, and that is necessary for giving them ideological authority and force.

\section{Method}

The study is a content analysis of 1,000 hours of television from the five largest broadcasters in Sweden, each of whom has a daily reach of more than 10 per cent. The broadcasters selected are the two public service operators, SVT1 and SVT2, and three of the commercial broadcasters, TV3, TV4, and Channel 5. The material has been selected in such a way as to represent the output of these five channels during the year 2015.

The analytical units in this study are the persons who appear on television, and the sample was derived by creating a still image from the recording at 10-minute intervals. The benefit of this method is that it cuts across all genres and types of output and gives a representative picture of the kinds of individuals (or social categorisations) that are most frequently occurring in the material. In total, we collected 5,500 sampling units (i.e., images) and 9,679 analytical units (since some of the sampling units contained several persons).

We coded the analytical units (i.e., each person appearing in a sample image) in relation to variables such as age, gender, occupation, and class, as well as in relation to what they are doing and how they are portrayed within the program. In addition to the persons appearing in each image, each sampling unit was also classified according to more general attributes, such as genre, country of origin etc. All coding was done with the program as context, for example, when deciding what importance the person has or what occupation s/he holds. Statistical significance has been tested using Pearson's r.

Regarding the concept of class, we take our starting point from the Marxist definition, and especially from the theoretical developments by Erik Olin Wright (Wright 1980, 1997, 2005). A Marxist starting point on class anchors the concept within the social relations of (capitalist) production. Class is not (necessarily) about income differences, cultural capital or social status; however, the category is determined by the objective power and resources that a person has as a result of their relationship with the means of production. The basis for our understanding of social class is hence a person's place in production, but also includes other power resources (for example, political power) and formal education, and hence also includes a more Weberian understanding of class (cf. Goldthorpe 2000). For example, high-level politicians, such as presidents and primeministers as well as power-holders from other social spheres (university chancellors, arch-bishops, etc.), are placed together with capitalists within the class position we label the "social elite".

The traditional Marxist approach results in what often is called a "two-class model" that differentiates between workers (all those who live off their labour) and capitalists (all those who live off the labour of others). This two-class model implies antagonistic relations between the two classes, since the interests of capitalists (owners) and workers 
(wage-labourers) are objectively opposite in the social arena, and because the power exerted by one class always stands in relation to the power of the other.

Nevertheless, it is obvious that these categories are very broad and that several complicated, compromised and negotiated positions are located between owners and wagelabourers. These are what Wright (1997: 10) calls "contradictory locations within class relations". The most important of these "contradictory locations" are managers in corporations and employed professionals (ibid.). In our analysis, therefore, we have divided the population into three groups that are defined by the power held by the individual to affect the living and working conditions of themselves and of others. These groups are here labelled the social elite, the middle class and the working class. ${ }^{2}$

The social elite is defined as people who have significant opportunities to influence their own living conditions and the living conditions of other people, through their position in the working world. Capitalists of different kinds, who live off their capital and the work of others, are the most important members of this group. However, this category also includes highly placed politicians and the top tier of managers and professionals who have many opportunities to exercise the power of capital, such as the CEOs of large companies. The middle class is here defined as employed professionals and managers - the functionaries of capital, who have some opportunities to exercise the power of capital - but also people that are employed to perform more menial tasks in an office environment, such as people occupying the lower positions in economic and technical departments at large companies. The middle class has, in relation to the social elites, relatively few opportunities to the change the living conditions of others, for example through hiring, firing, and making decisions about new technologies or changes in the labour process. Middle class persons have however, in relation to working class persons, relatively numerous opportunities to change their own living and working conditions, for example deciding how work tasks should be executed, where the work should be carried out, or using his or her social and educational capital to switch workplaces. This criterion is used in our analysis, for example, to distinguish between a middle-class office worker and a working-class person in a call centre environment, who has very little decision power over working conditions.

This operationalisation of social class still means that each class position is defined in a relatively broad way. Occasionally, in the analysis, we have thus chosen to look closer at the composition of a certain class. This is possible due to the fact that the coding scheme includes a variable that separates between 46 different areas of work and another variable that uses the Swedish Statistical Bureau's SEI-index to distinguish between different positions within the classes. This is particularly useful for unpacking the "middle" strata and to separate professionals from managers and from small entrepreneurs.

We think that the general benefit with the definition and operationalisation of class in this study is that it is sociologically and theoretically grounded, but that it at the same time is a model that is translatable to an "everyday" understanding of class and to popular language use. Most importantly, it is possible to use this operationalisation in relation to televisual material, since occupations are often manifest and possible to register in a content analysis.

During the research process, several measures were taken to ensure intercoder agreement, such as coder training, test coding, joint coding, and daily coder meetings with the coder group (made up of five people) to discuss difficult aspects and interesting cases. 
Several tests for intercoder agreement were also conducted and analysed according to Fleiss' kappa, Cohen's kappa and Krippendorff's alpha. Only one of the variables had to be excluded due to weak reliability, while the others gained sufficient reliability according to the three measures mentioned above. The average intercoder agreement for all the variables - according to Krippendorff's alpha - was 0.770 (H: 939, L: 687). ${ }^{3}$

\section{Social class as a televisual category}

Social class on television is rarely mentioned explicitly and is mainly constructed through references to people's occupational status. The first step in answering the question whether people appearing on television are categorised and represented along the lines of social class thus lies in finding out if it is possible to tell a person's occupational status from the televisual text. In our study, we found that it was possible to judge the occupation of a person appearing on television in 65 per cent of the cases. Occupational information is often given directly, and if not, is generally revealed in other ways, for example, through activities undertaken by the person or clothing (e.g., uniforms), or from the general context of the program. Using other signs of class belonging, such as references to capital and resources or representations of certain kinds of lifestyles, it was possible in this study to infer a person's social class in 77 per cent of all cases. ${ }^{4}$ It does not follow, however, from the fact that it is possible to recognise class belonging on television, that social class is a category that structures the televisual output. To show that it indeed is such a category, it is also necessary to show that social class matters for the social world of television in terms of valuations, hierarchies, and orders of visibility.

That there is a valuation in television's categorisation of social class is made apparent through at least three different aspects of television's representation of social class: (1) the visibility and invisibility of the social classes, (2) the differences in how people from different social classes are presented and portrayed and (3) the separation between social classes into televisual genres with different valuations.

1. In the television output of 2015 , only 9 per cent of the people occurring in the programs belong to the working class, while 76 per cent are middle-class persons. The working class (in Sweden as in most countries) is in reality about 40-50 per cent of the population (Ahrne 2008; Oskarson, Bengtsson \& Berglund 2012). This underrepresentation is nothing new or unique to the study at hand. On the contrary, a similar pattern has been visible in most class analyses of television, conducted within a range of national contexts and using various research designs (Butsch 1992; Ross 2008).

Table 1. The representation of social classes in Swedish television 2015 (per cent)

\begin{tabular}{lr}
\hline Working class & 9 \\
Middle class & 76 \\
Social elite & 15 \\
Sum & 100 \\
\hline
\end{tabular}

Comment: For information about how class is operationalised, see above. $\mathrm{N}=7,225$ 
Within the different social classes that appear on television, white-collar workers form the dominant group (29 per cent of all persons on television), and they mainly consist of doctors, psychologists, police officers, etc. that are often part of televisual narratives (both in fiction and news). Within the working-class segment, there is a clear tendency to depict people from the service sector, rather than working-class people in manufacturing. Working-class people within the service sector, such as waitresses, shop assistants, assistant nurses, hairdressers, and the like, make up 8 per cent of all people on television, while working-class people in manufacturing, transport, and industrial production are only 1 per cent of people visible on television (while making up around 20 per cent of the total workforce).

The results also show that it is more likely that people from the working class are depicted as belonging to the past $(p<0.001)$, and in modern society contemporariness is not a neutral description, but rather a value-laden concept. Of the working-class persons on television, 29 per cent are represented as living in a bygone historical era, compared to 17 per cent and 18 per cent, respectively, for the middle and upper classes. The working class, to a higher degree than the other social classes, is hence represented as a category that belongs to former times.

The relative absence of persons from a working-class background and the overrepresentation of people with middle- and upper-class backgrounds does not itself, in any obvious way, constitute a valuation of the different classes. It is sometimes said that it is part of the privilege and the power of the upper class that it evades the spotlight of the media. Although the relative absence of working-class people can serve as an indication that the interests, perspectives, worldviews, and identities of working-class people are given a low priority by the media, this absence still needs to be given further context to be rightly interpreted as a sign of low valuation. Part of that context can be constructed by looking at how people from the different social classes are portrayed and presented on television.

2. The results from our study show several aspects of how people from different social classes are presented on television. In the first instance, we coded each person in our research material according to his or her "significance for the program". A person was judged to be "very significant" or "significant" for the program if that person appeared recurrently throughout the program, or if that person played a principal role in that part of the program that constituted the core of the program, appeared several times in the program, or were part of a consecutive development of the program. "Less significant" persons were persons who appeared occasionally, but without being part of a consecutive development of the program. The results only show small differences, but show that people from the upper and middle classes are more likely to be portrayed as being of importance and vice versa (see Table 2).

Another way to analyse how the social classes are valued by television is to measure whether representatives of the different classes are appearing both visually and audibly, or if they are only visually or only audibly present. It is reasonable to suggest that a person who appears both audibly and visually is judged to be of higher importance than a person who appears only by being seen. That there is a valuation of the social classes on television is thus shown by the fact that social class correlates with audibility and visibility, in a pattern that is clearly hierarchical (see Table 3). In addition to 
Table 2. The significance of the different social classes in Swedish television programmes 2015 (per cent)

\begin{tabular}{lccc}
\hline & Working class & Middle class & Social elite \\
\hline Significance in the programme & 55 & 66 & 67 \\
Limited or no significance for the programme & 45 & 34 & 33 \\
Sum & 100 & 100 & 100 \\
\hline
\end{tabular}

Comment: A person is of significance in the programme if that person is the main character of the narrative, or if the person directly or indirectly is recurring throughout the programme. The correlation between class and significance is statistically significant ( $\mathrm{p}<0.001)$. $\mathrm{N}$ varies between 670 ("Working class") and 5,454 ("Middle class").

this, people from higher social classes are more frequently speaking to people of lower social class than the other way around. The results show three times as many occasions when a member of the social elite speaks to one or more persons belonging to one of the other classes as occasions when a working-class person speaks to a person belonging to a different social class. There are also twice as many occasions when middle-class persons speak to people from other classes as there are occasions when working-class people take the verbal initiative.

Table 3. The mode of appearance of different social classes in Swedish television programmes 2015 (per cent)

\begin{tabular}{lccc}
\hline & Working class & Middle class & Social elite \\
\hline Appears both audially and visually & 32 & 37 & 53 \\
Appears only visually & 68 & 63 & 47 \\
Sum & 100 & 100 & 100 \\
\hline
\end{tabular}

Comment: A person was coded as appearing both audially and visually if that person was speaking in the analytical unit (i.e. the freeze-frame). The correlation between class and mode of appearance is statistically significant $(\mathrm{p}<0.001)$. N varies between 621 ("Working class") and 4,405 ("Middle class").

In the analysis of the fictional programs in our material, we also coded things that related to the narrative of the program and the way in which the characters in the narrative are represented. Consequently, these analyses do not cut across genres like the other analyses, but they do provide a more nuanced way of analysing the valuation of social class. The variables only cover some aspects of the narrative and character presentation, but they give an indication of the differences in the attribution of positive and negative characteristics to people from different social classes. Firstly, in fictional content that is structured according a schematic opposition between good and evil, 97 per cent of the good and virtuous belong to the upper- and middle-class (e.g. combating or opposing evil forces), while only 3 per cent of the good and virtuous belonged to the working-class $(\mathrm{p}<0.001)$. Secondly, the results show that people from the middle and upper class are twice as likely as working-class people to be described as leading a life with clear goals and aspirations $(\mathrm{p}<0.001)$. Furthermore, class position also affects in a significant way the level of nuance in how people are portrayed on television (see Table 4). The general tendency is that the higher in the class hierarchy that a person is placed, the more social relations - of different kinds - that person has, and the social relations are also of greater importance for the narrative. One example 
of this is how the personal relations of individuals from different class positions are represented in television programmes. It is more common that people from the upper and middle classes are depicted as having intensive and important relationships with family members, children, friends, lovers, and spouses than is the case for workingclass people. It is more than twice as common that upper-class people are depicted as having a strong and important relationship with their children than is the case with people from the working class. Of the people on television who are represented as engaged in a romantic relationship with another person, and where this relationship is of importance for the program as such, twice as many of these persons belong to the social elite, as to the working class.

Table 4. Social relations and social class in drama and film on Swedish television 2015 (per cent)

\begin{tabular}{lccc}
\hline & Working class & Middle class & Social elite \\
\hline $\begin{array}{l}\text { Has no social relations of significance } \\
\text { to the narrative }\end{array}$ & 89 & 83 & 78 \\
$\begin{array}{l}\text { Has social relations of some or great } \\
\text { importance to the narrative }\end{array}$ & 11 & 17 & 22 \\
Sum & 100 & 100 & 100 \\
\hline
\end{tabular}

Comment: A social relation is defined as a relation of personal significance to a person. Formal relations, for example between an employer and an employee, are not included (unless a formal relation also involves a personal relation). N varies between 947 ("Social elite") and 5,475 ("Middle class").

In sum, this points to the fact that the higher in the class hierarchy a person is positioned, the higher the probability that the person will be awarded subjectivity and be depicted in more "human" and nuanced ways. ${ }^{5}$ To be awarded great levels of subjectivity is a form of implicit valuation, not least since social capital has become increasingly important in society; to possess such capital (networks, friends, family, relations) is a marker of status and success.

3. A third way of measuring television's valuation of the social classes is to put their relative visibility/invisibility in relation to television's genre system. When this is done, it can be demonstrated that the evaluative character of their relative visibility/invisibility is further strengthened by a pattern that on a regular basis puts people from the working class in genres with a relatively low status, while middle- and upper-class people are found in other, more high-status segments of the televisual output. This also means that television in general, as covered by this study, is class segregated, with different social classes inhabiting different parts of the television landscape.

For one thing, the different classes are likely to appear in different channels (see Table 5). The two public service broadcasters (SVT1 and SVT2) have the lowest rate of working-class participants in their programs, 7 per cent in both public service channels. Among the commercial broadcasters in the sample the class composition varies. TV3, the channel with most reality programming and a low rate of original productions, has as many as 18 per cent working-class people in its output, and 34 per cent of all workingclass people in the entire sample are seen on this television channel. 
Table 5. The appearance of the different social classes on the five television channels with largest reach in Sweden 2015 (per cent)

\begin{tabular}{lrrrrc}
\hline & SVT1 & SVT2 & TV3 & TV4 & Channel 5 \\
\hline Working class & 7 & 7 & 18 & 12 & 11 \\
Middle class & 80 & 62 & 55 & 84 & 74 \\
Social elite & 13 & 32 & 28 & 4 & 15 \\
Sum & 100 & 101 & 101 & 100 & 100 \\
\hline
\end{tabular}

Comment: Appearance includes speaking and/or appearing in picture, but also being spoken about. SVT1 and SVT2 are public service channels, while TV4 is a commercial channel with some public service obligations. TV3 and Channel 5 are both commercial channels. N varies between 1,232 (TV4) and 1,733 (Channel 5). The correlation between class and channel is statistically significant $(\mathrm{p}<0.001)$.

There is a range of plausible explanations for these differences, for example, different target audiences among the broadcasters and differences in how the content is produced and by whom (see Hesmondhalgh forthcoming, for a discussion on the role of production for class representations in the media). Most certainly, however, these differences mirror the genre mix of the different broadcasters (see Table 6). The commercial stations mainly carry reality and drama programs, and the results show that working-class people are most commonly represented on reality television (17 per cent working class) and in television drama (14 per cent working class). In more "serious" forms of programming, on the other hand, there is almost no representation of working-class people, whatsoever; in news and factual programming only 4 per cent belong to the working class $(\mathrm{p}<0.001)$. When computing these statistics, we have excluded employees of the broadcasters (e.g., program hosts, news reporters, etc.), as taking them into account would increase the dominance of the middle class in all genres.

Table 6. Social classes in different genres on Swedish television in 2015 (per cent)

\begin{tabular}{lcccc}
\hline & $\begin{array}{c}\text { News and factual } \\
\text { programming }\end{array}$ & Drama and film & Entertainment & Reality TV \\
\hline Working class & 4 & 14 & 6 & 12 \\
Middle class & 69 & 73 & 85 & 84 \\
Social elite & 27 & 13 & 9 & 4 \\
Sum & 100 & 100 & 100 & 100 \\
\hline
\end{tabular}

Comment: The correlation between class and genre is statistically significant $(\mathrm{p}<0.001)$. N varies between 853 ("News and factual programming") and 1,527 ("Drama and film").

Through the analysis, we can see what could be labelled as a ghettoisation of television, or the creation of "gated communities" in which the social classes are compartmentalised into different televisual spaces: different channels, different genres, and different programs.

Class segregation, however, also runs through the programs themselves. As mentioned above the analytical unit in this analysis is the image that we retrieve through pausing the recorded broadcast every 10th minute and coding all persons within that image according to factors such as class, gender, age, and so on. From this we can conclude that the most common televisual images in our study are depictions of one middle-class person (37 per cent of output), two middle-class persons together (16 per cent), or one 
person from the upper class ( 8 per cent). In general, based on the materials in this study, relations between different social classes - that is, persons of different classes visible at the same time in a sample - only occur in 10 per cent of the entire output, which means that class interaction is rare in contemporary television.

\section{Discussion}

In this article, we have shown that television systematically values people according to class and that class, even though it is seldom made manifest, is a central category structuring televisual output.

The working class has always been underrepresented on television (Smythe 1954; Butsch 2003), and this study adds further evidence that this still is the case. While the working class in Sweden makes up around 40-50 per cent of the population, it accounts for only 10 per cent of the people appearing on television. In this article we have, however, shown that the working class is not only underrepresented, it is also constructed as part of a value hierarchy of social relations in which the working class is constantly placed at the bottom. Working-class people on television are portrayed as lacking individuality, social skills, and authority, and are generally conceived as less important than people belonging to the middle and upper classes. The important point here is that this formation of class as a category and the valuation of this social category is systematic within the television output as a whole. The significance of this particular ideological construction is that it is so ubiquitous that it is almost beyond the point of contestation. It is not presented as a fact among others, but rather as a basic structure of the discourse of television. The existence of different classes and the status hierarchy structuring their relations might thus be perceived, even if this isn't analysed in the present study, as a naturally existing condition, rather than as a socially and culturally constructed fact. The ideological message of television is visible in the repetition and pervasiveness of social categorisations across all types of output, on a daily basis. The valuation of different social classes and the ways in which they are portrayed and offered agency is an inherent part of the ordinariness and routineness of the medium itself. It is also against this background - or within this symbolic environment as a totality - that the specificities of ideological and stereotypical depictions of working-class people in different programs and genres (for example in reality television-programs, as have been documented in previous qualitative research) become meaningful and attain their ideological force. Large-scale content analysis like the one conducted here can hence strengthen and support - as well as serve as a background for - more qualitative and critical close readings of specific televisual texts and genres.

In our view, content analysis is an important tool for deepening and developing analysis of the ideological dimensions of the media, and of television in general. As the ubiquitous and massive flow of media content produces a constantly present, ordinary, and taken-for-granted background to social life, it also repeats, iterates and naturalises social patterns and categories. Content analysis offers a way forward in taking on this dimension of the media, and it becomes increasingly important in a developing media landscape. As has been shown in neighbouring fields, such as comparative literature, new (media) technologies can also be used to automatize and simplify analyses of large (digital) materials. The method of "distant reading" developed by Franco Moretti (Moretti 2013) is of interest here. Moretti, coming from the field of Marxist aesthetics, 
has developed tools for the analysis of large materials, in relation to both content and form, not only to analyse the longue durée of literary development but also to better analyse specific genres and texts from a critical perspective. We have in a previous piece discussed the possibilities of a "distant viewing" for analysis of televisual content (Stiernstedt \& Jakobsson 2017a). Even though the technical means of automated analysis still exists only in embryonic forms - for example, in the automated video analytics used by security companies, the military, and the police - more sophisticated technologies might open new avenues for research in the future. Contemporary media development, in which moving images and audio-visual content are exploding in online environments, also calls for more attention to such possibilities also within the (critical) media research.

\section{Notes}

1. The differences between categories of social class and celebrity should not be exaggerated. Even if the category of media celebrity is unthinkable without the media, it is not clear whether this category is constructed as a genuinely new category, together with the rise of the modern media system, or whether it builds on older traditions of celebrity, such as the courtly traditions of appearing in public in front of an audience. Secondly, media celebrities are rarely produced and reproduced by the media in isolation from other social spheres and structures. The media coproduces media celebrities together with market structures and processes of commodification.

2. Peasants is a class category of its own in our operationalisation, however it has been excluded from the analysis in this article. Business owners is sometimes coded as middle-class, sometimes as working-class and sometimes as belonging to the social elite, dependent on the size of the business and the formal power and influence that their specific position in the field of social production affords them through their role as business-owners. The operationalisation of class also includes categories for "underclass/ socially excluded", for example extremely poor, homeless people or people that due to other reasons have no standing in the production whatsoever.

3. The methodological description of the project and the discussion of class has been published previously, see Stiernstedt \& Jakobsson (2017a) and Stiernstedt \& Jakobsson (2017b).

4. Sometimes class could be coded without knowledge of occupation, but it was only allowed when other information clearly and unambiguously showed that a person belonged to a given class position even though the specific occupation was not openly stated. This would have to be a combination of things such as clothing, living conditions, material possessions (or lack thereof), cultural consumption, language use, friends and social activities, physical environments, etc. The rule was that at least four elements of this kind should point to a given class position for coding to be allowed.

5. Of the results on relationships between class position and relationships to others four correlations were found to be significant $(\mathrm{p}<0.001)$. The statistically significant results concerns relations to siblings, spouses, lovers and other close friends. The results concerning relations to children and parents did however not achieve statistical significance.

\section{References}

Ahrne, Göran (2008). Det sociala landskapet: En sociologisk beskrivning av Sverige från 1950-talet till början av 2000-talet. [The Social Landscape: A Sociological Description of Sweden from 1950 until the Start of the 21th century]. Gothenburg: Korpen.

Bourdieu, Pierre (1989). Social Space and Symbolic Power. Sociological Theory, 7(1): 14-25.

Bromley, Roger (2000). The Theme That Dare Not Speak Its Name: Class and Recent British Film, pp. 51-68 in Munt, Sally R. (ed.) Cultural Studies and the Working Class. London: Cassell.

Bullock, Heather E.; Fraser Wyche, Karen \& Williams, Wendy R. (2001). Media Images of the Poor. Journal of Social Issues, 57(2): 229-246.

Butsch, Richard (1992). Class and Gender in Four Decades of Television Situation Comedy: Plus Ça Change. Critical Studies in Mass Communication, 9(4): 387-399.

Butsch, Richard (2003). A Half Century of Class and Gender in American TV Domestic Sitcoms. Cercles, 8: 16-34.

Couldry, Nick (2003). Media Rituals: A Critical Approach. London: Routledge. 
Couldry, Nick (2008). Media Discourse and the Naturalisation of Categories, pp. 67-87 in Wodak, Ruth \& Koller, Veronika (eds.) Handbook of Communication in the Public Sphere. Berlin: Walter de Gruyter.

Couldry, Nick (2011). Class and Contemporary Forms of 'Reality' Production, or Hidden Injuries of Class, pp. 33-44 in Wood, Helen \& Skeggs, Beverley (eds.) Reality Television and Class. Basingstoke: Palgrave Macmillan.

Crompton, Rosemary (2008). Class and Stratification. Cambridge: Polity.

Durkheim, Émile \& Mauss, Marcel (1963). Primitive Classification. London: Cohen \& West.

Hall, Stuart. 1977. Culture, the Media and the 'Ideological Effect', pp. 315-349 in Curran, James; Gurevitch, Michael \& Woollacott, Janet (eds.) Mass Communication and Society. London: Edward Arnold.

Harrits, Gitte Sommer \& Østergaard Møller, Marie (2011). Categories and Categorization: Towards a Comprehensive Sociological Framework. Distinktion: Journal of Social Theory, 12(2): 229-247.

Hesmondhalgh, David (forthcoming). How Media Production Can Help Explain the Media's Failure to Represent the Working Class. In Deery, June \& Press, Andrea (eds.) Media and Class. New York: Routledge.

Lakoff, George (1987). Women, Fire, and Dangerous Things: What Categories Reveal about the Mind. Chicago: University of Chicago Press.

Mantsios, Gregory (2003). Media Magic: Making Class Invisible. In Rothenberg, Paula S. (ed.) Race, Class and Gender in the United States. New York: MacMillan.

McGarty, Craig (1999). Categorization in Social Psychology. Thousand Oaks: SAGE.

Meloy, Mike (2009). From Kid Nation to Caste Nation: Mobility, Privilege, and the Paradox of Class on Reality Television. The Journal of American Popular Culture, 8(1).

Moretti, Franco (2013). Distant Reading. London: Verso.

OECD (2017). OECD Economic Surveys Sweden [online]. Available at http://www.oecd.org/eco/surveys/ Sweden-2017-OECD-economic-survey-overview.pdf [Accessed 8 January 2017].

Oskarson, Maria; Bengtsson, Mattias \& Berglund, Tomas (2010). En fråga om klass: Levnadsförhållanden, livsstil, politik [A Question of Class: Living Conditions, Lifestyle, Politics]. Malmö: Liber.

Palmer, Gareth (2004). The New You: Class and Transformation in Lifestyle Television, pp. 173-190 in Holmes, Su \& Jermyn, Debroah (eds.) Understanding Reality Television. London: Routledge.

Perks, Lisa Glebatis (2007). The Nouveau Reach: Ideologies of Class and Consumerism in Reality-Based Television. Studies in Language and Capitalism, 2: 101-118.

Ross, Sven (2008). Klasstolkningar: En receptionsanalys av hur klassaspekter uppfattas i Tre kärlekar, Falcon Crest och TV-nyheter [Class Interpretations: A Reception Analysis of Aspects of Social Class in Tre Kärlekar, Falcon Crest and TV-news]. Stockholm: Stockholms universitet.

Sayer, R. Andrew (2005). The Moral Significance of Class. Cambridge: Cambridge University Press.

Skeggs, Beverley (2004). Class, Self, Culture. London: Routledge.

Skeggs, Beverley (2005). The Making of Class and Gender through Visualizing Moral Subject Formation. Sociology, 39(5): 965-982.

Smythe, Dallas W. (1954). Reality as Presented by Television. The Public Opinion Quarterly, 18(2): 143-156.

Stiernstedt, Fredrik \& Peter Jakobsson (2017a). Watching Reality From a Distance: Class, Genre and Reality Television. Media, Culture \& Society, 39(5): 697-714.

Stiernstedt, Fredrik \& Peter Jakobsson (2017b). Ghettos and Gated Communities in the Social Landscape of Television: Representations of Class in 1982 and 2015, pp. 255-272 in O'Neill, Deidre \& Mike Wayne (eds.) Considering Class: Theory, Culture and the Media in the 21st century. Leiden: Brill Academic Publishers.

Therborn, Göran (1999). The Ideology of Power and the Power of Ideology. New York: Verso.

Thompson, John B. (1984). Studies in the Theory of Ideology. Berkeley: University of California Press.

Thompson, John B. (1990). Ideology and Modern Culture: Critical Social Theory in the Era of Mass Communication. Cambridge: Polity.

Wood, Helen \& Skeggs, Beverley (2011). Reality Television and Class. London: BFI.

Wright, Erik Olin (1980) Varieties of Marxist Conceptions of Class Structure. Politics \& Society, 9(3): 323370 .

Wright, Erik Olin (1997). Class Counts: Comparative Studies in Class Analysis. Cambridge: Cambridge University Press.

Wright, Erik Olin (2005). Approaches to Class Analysis. Cambridge: Cambridge University Press.

PETER JAKOBSSON, Senior Lecturer and Researcher, School of Culture and Education, Södertörn University, peter.jakobsson@sh.se

FREDRIK STIERNSTEDT, Senior Lecturer and Researcher, School of Culture and Education, Södertörn University, fredrik.stiernstedt@sh.se 